\title{
Binding of the Bi (III) Complex of Naringin with $\beta$-Cyclodextrin/Calf Thymus DNA: Absorption and Fluorescence Characteristics
}

\author{
Sameena Yousuf and Israel V. Muthu Vijayan Enoch \\ Department of Chemistry, School of Science and Humanities, Karunya University, Coimbatore, Tamil Nadu 641 114, India
}

Correspondence should be addressed to Israel V. Muthu Vijayan Enoch; drisraelenoch@gmail.com

Received 21 January 2014; Revised 1 April 2014; Accepted 23 April 2014; Published 5 June 2014

Academic Editor: Shigehiko Takegami

Copyright (c) 2014 S. Yousuf and I. V. M. V. Enoch. This is an open access article distributed under the Creative Commons Attribution License, which permits unrestricted use, distribution, and reproduction in any medium, provided the original work is properly cited.

\begin{abstract}
Naringin-Bi (III) complex (Narb) was prepared and analysed by UV-Visible absorption and fluorescence measurements. The inclusion complex of Narb with $\beta$-Cyclodextrin $(\beta$-CD) was characterized by the UV-Visible absorption, Infrared, scanning dlectron microscopic, and X-ray diffractometric techniques. The stoichiometry of the inclusion complex of Narb with $\beta$-CD was $1: 1$ with a binding constant of $5.18 \times 10^{2} \mathrm{~mol}^{-1} \mathrm{dm}^{3}$. The interaction of Narb with Calf Thymus DNA (ctDNA) was investigated in the presence and the absence of $\beta$-CD. The binding constants for the interaction of Narb with ctDNA in the absence and the presence of $\beta$-CD were $1.29 \times 10^{5} \mathrm{~mol}^{-1} \mathrm{dm}^{3}$ and $6.89 \times 10^{4} \mathrm{~mol}^{-1} \mathrm{dm}^{3}$, respectively. The Stern-Volmer constants for the interaction of Narb with ctDNA in the absence and the presence of $\beta$-CD were $1.25 \times 10^{4} \mathrm{~mol}^{-1} \mathrm{dm}^{3}$ and $5.10 \times 10^{3} \mathrm{~mol}^{-1} \mathrm{dm}^{3}$, respectively. The lowering of the binding affinity and the $K_{\mathrm{sv}}$ were observed for the interaction of Narb with ctDNA in the presence of $\beta$-CD.
\end{abstract}

\section{Introduction}

In vitro study on the binding of small molecules such as metal complexes, porphyrins, natural antibiotics, and simple aromatic carbons with DNA can contribute to the design of new promising anticancer agents for clinical use [1]. Such interaction is important for knowing the mechanism of drug action of specific DNA targeted drugs. This can lead to structural changes of DNA to accommodate complex formation [2]. Many flavonoid based small molecules have been studied for DNA binding due to their nontoxicity [3]. Among them, Naringin (Figure 1) is an important flavonoid. The role of Naringin in human metabolism has been reported [4].

The importance of metal bound organic species resulted in the analysis for DNA binding. Adopting fluorescence spectroscopy can enlighten the analysis mainly in two ways, namely, (i) to know the fluorescence enhancement or quenching, (ii) investigating the dynamics of the molecules in solution. Very few results have been reported for the comparison on the fluorescence changes in organic species and its bismuth complexes interacting with ctDNA. For example the bismuth complex of Morin has been reported to bind differently with DNA compared to the binding of Morin [5]. It is reported that the stoichiometry on the binding with $\beta-C D$ and the quenching type are affected by the Bismuth complexation with the organic fluorophore [6]. Bismuth forms stable complex with the nonpolar aliphatic, aromatic, acidic, and basic biologically relevant ligands. It is reported that the complexes of $\mathrm{Bi}$ (III) metal ion are stable even in strongly acidic solutions, over a wide $\mathrm{pH}$ range [7]. Bismuth is one of those rare elements that are considered to be safe because of being nontoxic and noncarcinogenic despite its heavy metal status and having high avidity for coordination with the biologically important molecules making them nonfunctional due to which serious circumstances may arise having negative impact on the biological system. Though the use of compounds of bismuth was banned in few developed countries after reports about toxicity of Bismuth in the 1970s, bismuth salts are still used in medicine [8-10]. Bismuth $\left(\mathrm{Bi}^{3+}\right)$ compounds have been widely used in the clinic for centuries because of their high effectiveness and low toxicity 


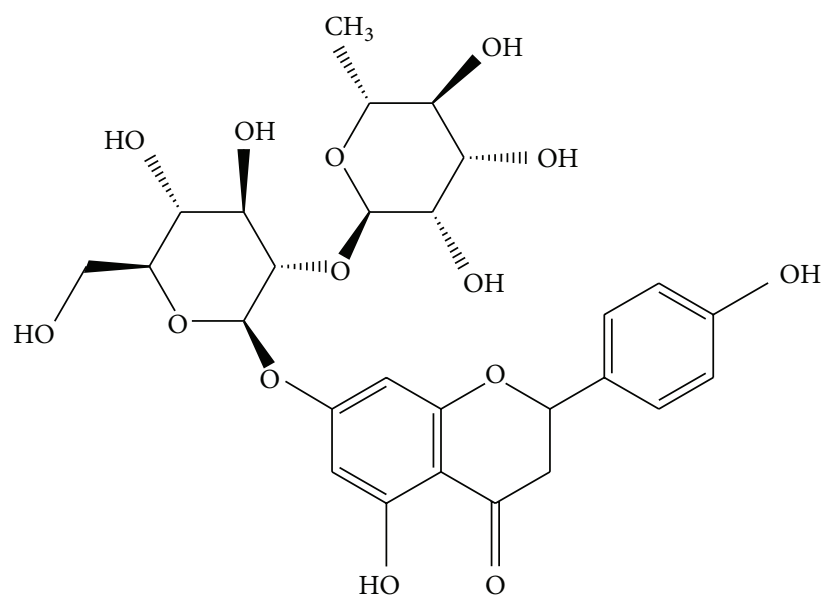

FIgURE 1: Molecular structure of Naringin.

in the treatment of a variety of microbial infections, including syphilis, diarrhea, gastritis, and colitis. Bismuth compounds exhibit anticancer activities; ${ }^{212} \mathrm{Bi}$ and ${ }^{213} \mathrm{Bi}$ compounds have also been used as targeted radiotherapeutic agents for cancer treatment and furthermore they have the ability to reduce the side effects of cisplatin in cancer therapy [7]. It is well known that the unique amphiphilic characteristics of Cyclodextrins make $\beta$-Cyclodextrin particularly important for the inclusion complexation studies especially with flavonoids to overcome the aqueous solubility/bioavailability problem. Moreover, it is employed as a host medium to study the interaction between flavonoid based small molecule and DNA [11]. The present work deals with the preparation of Bi (III) complex of Naringin and the analysis of the interaction of $\mathrm{Bi}$ (III) complex of Naringin with $\beta$-CD/ctDNA. The influence of $\beta$-CD encapsulation on the binding of Narb with ctDNA is investigated.

\section{Materials and Methods}

2.1. Instrument. Absorption measurements were performed with a double beam UV-Visible spectrophotometer (Jasco$\mathrm{V}$ 630) using $1 \mathrm{~cm}$ path length cells. Fluorescence spectra were recorded on a Fluorescence spectrophotometer (Cary Eclipse) equipped with Xenon lamp. Both the excitation and the emission band widths were set up at $5 \mathrm{~nm}$. An IR spectrum was recorded with $\mathrm{KBr}$ pellets on a Perkin-Elmer spectrum RXI, USA. Ultrasonicator PCI 9L 250H, India, was used for sonication. $\mathrm{pH}$ values were maintained using an Elico LI $120 \mathrm{pH}$ meter, India. The solid inclusion complex surface topology was imaged by JEOL Model JSM 6360 scanning electron microscope (SEM), Japan. The diffraction pattern of the crystal structure of the inclusion complex was reported by Shimadzu XRD 6000 X-ray diffractometry, Japan.

2.2. Materials. Naringin(7-[4,5-dihydroxy-6-(hydroxymethyl)3-(3,4,5-trihydroxy-6-methyloxan-2-yl)oxyoxan-2-yl] oxy-5hydroxy-2-(4-hydroxyphenyl)-2,3-dihydrochromen-4-one) was obtained from Sigma, India. ctDNA purchased from Genei (Merck), India, was used as such without further purification. The stock solution of ctDNA was prepared by diluting the ctDNA in $50 \mathrm{mmol}$ of $\mathrm{NaCl}$. The concentration of diluted ctDNA was analyzed by using the UV-Visible absorption spectroscopic technique. $10 \mathrm{mmol}$ acetate buffers $(\mathrm{pH}, 3.5)$ were used to maintain the $\mathrm{pH}$. The purity of ctDNA was in the range of 1.8 to 1.9. Bismuth (III) nitrate, obtained from Qualigens, India, was used as such. $\beta$-CD was purchased from HiMedia, India.

2.3. Naringin-Bi (III) Complex Synthesis. $0.2290 \mathrm{gm}$ of $\mathrm{BiNO}_{3}$ was dissolved in concentrated $\mathrm{HCl}$ and made up to $50 \mathrm{~mL}$ by water. $1.7414 \mathrm{gm}$ of Naringin was dissolved in $650 \mathrm{~mL}$ water, added to $\mathrm{BiNO}_{3}$ solution and kept for sonication for 2 to 3 hours. Its $\mathrm{pH}$ was fixed at around 3 with sodium hydroxide, heated to $60^{\circ} \mathrm{C}$ for one hour and kept for evaporation to half the volume and left at room temperature for 24 hours. The precipitate was then filtered out and recrystallized. The greenish yellow solid thus obtained was characterized by spectroscopic techniques.

2.4. Preparation of Inclusion Complex of Naringin-Bi (III) (Narb) with $\beta$-Cyclodextrin. Narb $\left(0.01 \mathrm{~mol} \mathrm{dm}^{-3}\right)$ was prepared in methanol and an equimolar amount of $\beta-C D$ was dissolved in doubly distilled water separately. A solution of Narb was added slowly to the solution of $\beta-\mathrm{CD}$ at room temperature in an Ultrasonicator and maintained for $30 \mathrm{~min}$. Then the mixture was warmed to $60^{\circ} \mathrm{C}$ for 1 hour and kept at room temperature for two days. The solid thus obtained was collected and analyzed by UV-Visible, IR spectrometry, scanning electron microscopy, and X-ray diffraction techniques.

2.5. Preparation of Working Solutions. Working solutions were prepared by an appropriate dilution of stock solutions of Narb, $\beta$-CD, and/or ctDNA. Owing to the poor solubility of Narb in water, the stock solution was made in methanol. The test solutions were having the concentration of methanol as $1 \%$. All reagents and solvents used were of spectral 
grade which were used without further purification. Doubly distilled water was used throughout. All experiments were carried out at an ambient temperature of $25 \pm 2^{\circ} \mathrm{C}$. The test solutions were homogeneous after all the additives were added and the absorption and the fluorescence spectra were recorded against the appropriate blank solutions.

\section{Results and Discussion}

3.1. Interaction between Naringin and Bi (III) Ions. The binding of Naringin (Narg) with ctDNA by using $\beta-C D$ as an encapsulating molecule was studied [4]. It has been reported that the bismuth complexation of organic fluorophore influences the fluorophore-ctDNA binding $[5,6]$. Narg possesses reactive centers for $\mathrm{Bi}$ [III] interaction, which might influence the normal binding of Narg moiety with ctDNA. The titration of Naringin with $\mathrm{Bi}$ (III) is carried out to find the ligand to metal ratio in solution using absorption measurements. The UV-Visible absorption spectra of Narg with increasing concentration of Bi (III) are shown in Figure 2. Narg showed two bands at $283 \mathrm{~nm}$ and $327 \mathrm{~nm}$. At the addition of Bi (III), the absorbance of dihydrochromene-4-one peak of Narg increased gradually. The stoichiometry of the complex was determined using the mole ratio method [5]. (inset of Figure 2). The result of the method suggested the formation of $2: 1$ complexes between Narg and Bi (III). This is evidenced by the intersection at $\mathrm{Bi}$ (III)/[Narg] of 0.5 . The initial absorbance shown at 0.4627 a.u. is due to the absorbance of Narg alone. The addition of $\mathrm{Bi}$ (III) resulted in the increase in the absorbance due to the complexation between Narg and $\mathrm{Bi}$ (III). The increase in absorbance at $283 \mathrm{~nm}$ is small when the ratio (Bi (III)/[Narg]) is below 1 . The physical and chemical heterogeneity can affect the metal binding to ligand. Narg is polyfunctional molecule which contains different types of complexing sites. The degree of aggregation and coiling of the Naringin molecule limits the accessibility of some ligand sites to larger metal ions in the initial stages of interaction between Naringin and Bi (III), leading to the minor increase in the absorbance of the complex. Further increase in the absorbance of the complex might be due to the presence of excess of metal ions and its accessibility to Narg. An IR spectrum was recorded to validate the interaction between Narg and Bi (III). The comparison of the spectral data of Narg and Narb gave information about the formation of the metal complex. The infrared spectrum of Narg and its Bi (III) complex, Narb, were characterized with the added $\mathrm{KBr}$ pellets. The position of $\gamma(\mathrm{C}=\mathrm{O})$ is diagnostic for the coordination complexation with $\mathrm{Bi}$ ion, which shifts IR band towards a smaller wave number. The IR spectrum showed bands at $1645 \mathrm{~cm}^{-1}(\nu \mathrm{CO})$ and $1298 \mathrm{~cm}^{-1}(\nu \mathrm{C}-\mathrm{O}-\mathrm{C})$ for Naringin [12]. Upon binding to Bi (III) and forming complex Narb, these bands shifted to $1638 \mathrm{~cm}^{-1}$ and $1289 \mathrm{~cm}^{-1}$, respectively, suggesting an interaction of the $\mathrm{Bi}$ (III) ion with the condensed ring via the carbonyl group, in position 4, and by the oxygen of the hydroxyl group in position 5 , in agreement with UV-Visible data (Figure 3). Moreover, there was formation of new bands found at $820,490-510 \mathrm{~cm}^{-1}$ in the Narb complex. The above observation might be due to the

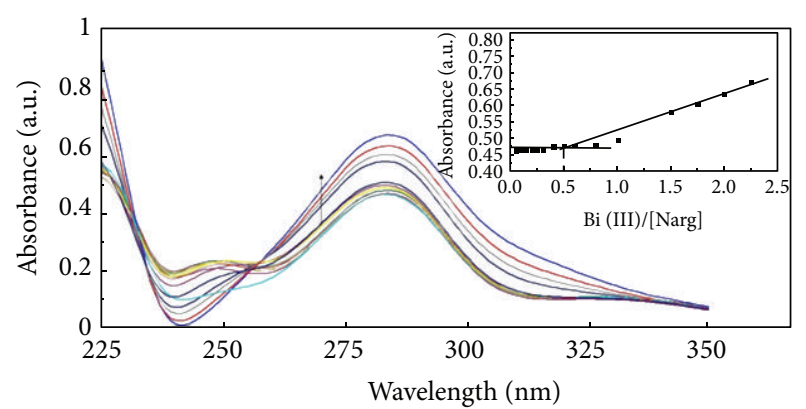

FIgURE 2: Absorption spectra of Naringin with different concentrations of $\mathrm{Bi}$ (III) (inset: the plot of $\mathrm{Bi}$ (III)/[Naringin] against absorbance).

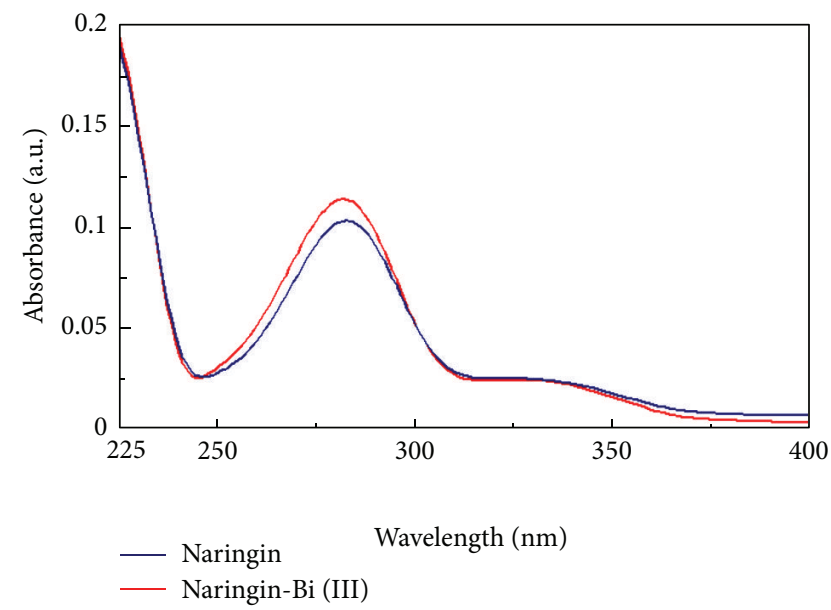

Figure 3: Absorption spectra of Naringin $\left(4 \times 10^{-6} \mathrm{~mol} \mathrm{dm}^{-3}\right)$ and Naringin-Bi (III) complex $\left(4 \times 10^{-6} \mathrm{~mol} \mathrm{dm}^{-3}\right)$.

formation of $\mathrm{M}-\mathrm{O}$ bond in the complex. The comparison on IR spectral bands of Narb and its inclusion complex is given in Table 1. It shows the changes in the frequency of Narb after interaction with $\beta$-CD. The changes in frequency of Narb suggested the interaction of Narb with $\beta$-CD.

The SEM images of Narg, Narg- $\beta-C D$, Narb, and the Narb- $\beta$-CD inclusion complex are given in Figures 4(a) and $4(\mathrm{~d})$, respectively. The morphology of Narg, Narb, and its inclusion complex is significantly different from one another. The complex, Narb, and its inclusion complex are found to appear as rod-like structures in comparison with Narg and its inclusion complex. The solid inclusion complex was found to be readily soluble in water compared to that of Narg and Narb.

The XRD patterns of Narg, Narb, and the solid inclusion complex formed are given in Figure 5. It showed a number of intense peaks especially for Narg and Narb, indicating sharp crystal structures of the complex. The inclusion complexation of Narg and Narb resulted in the decrease of intense peaks. It is more pronounced in the case of inclusion complex of Narb- $\beta$-CD. The X-ray pattern of $\beta$-CD was referred to from the report by Farcas et al. [13]. This difference might be due to the formation of new phases with different degrees of 


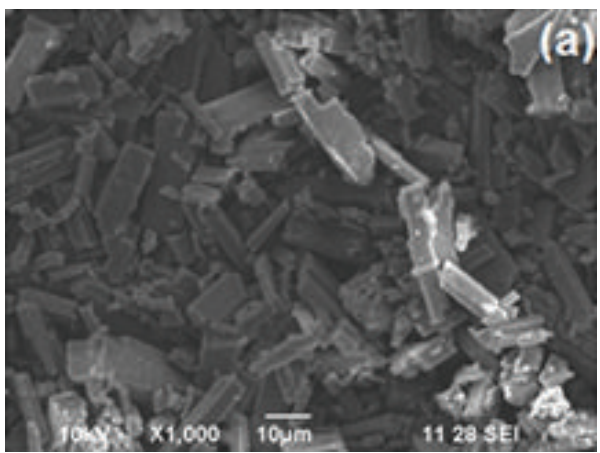

(a)

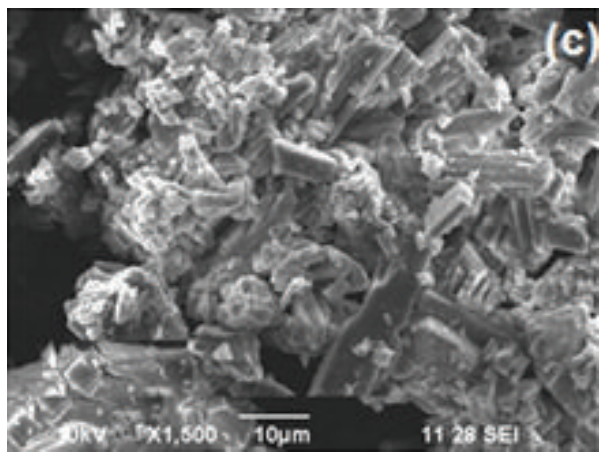

(c)

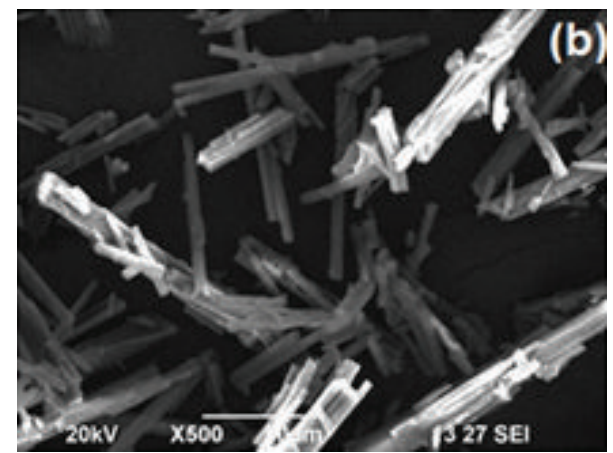

(b)

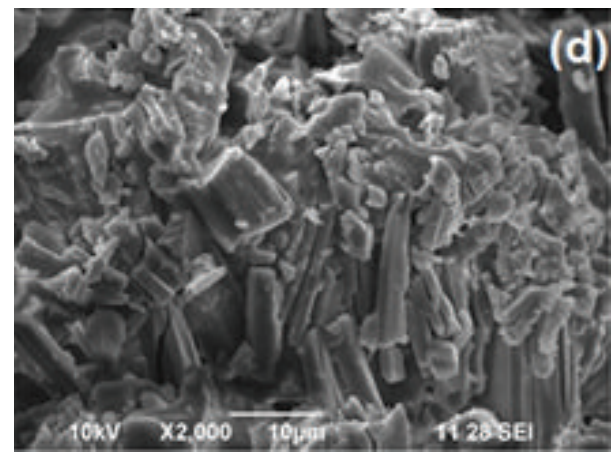

(d)

FIgURE 4: Scanning electron microscope images of (a) Naringin, (b) Naringin-Bi (III) complex, (c) Naringin- $\beta$-CD inclusion complex, and (d) Naringin-Bi (III)- $\beta$-CD inclusion complex.

TABLE 1: Comparison on the wave numbers of Naringin-Bi (III) and its $\beta$-CD inclusion complex by infrared spectroscopy.

\begin{tabular}{|c|c|c|}
\hline Type of bonds & $\begin{array}{c}\text { Naringin-Bi (III) } \\
\text { Wave number }\left(\mathrm{cm}^{-1}\right)\end{array}$ & $\begin{array}{c}\beta \text {-CD inclusion complex of Naringin-Bi (III) } \\
\text { Wave number }\left(\mathrm{cm}^{-1}\right)\end{array}$ \\
\hline $\mathrm{O}-\mathrm{H}$ stretching vibration & 3418 & 3375 \\
\hline \multirow{2}{*}{ Carbonyl bond $\mathrm{C}=\mathrm{O}$} & \multirow[t]{2}{*}{1638} & 1641 \\
\hline & & 1514 \\
\hline \multirow{2}{*}{ Aromatic $\mathrm{C}=\mathrm{C}$ stretching } & 1510 & - \\
\hline & 1445 & - \\
\hline \multirow{3}{*}{ C-O stretching } & 1359 & 1383 \\
\hline & 1283 & - \\
\hline & 1192 & - \\
\hline \multirow{3}{*}{ Aliphatic C-H stretching } & 2924 & - \\
\hline & 2353 & 2360 \\
\hline & 2330 & - \\
\hline \multirow{4}{*}{$-\mathrm{C}-\mathrm{OH}$ stretching } & 1113 & 1032 \\
\hline & 1069 & - \\
\hline & 891 & - \\
\hline & 824 & - \\
\hline \multirow{4}{*}{$\begin{array}{l}\text { Deformation vibrations }-\mathrm{C}-\mathrm{H} \text { outside plane, related to } \\
\text { substitution of aromatic rings of multiring compounds }\end{array}$} & 629 & 616 \\
\hline & 561 & 495 \\
\hline & 469 & 482 \\
\hline & 451 & \\
\hline
\end{tabular}




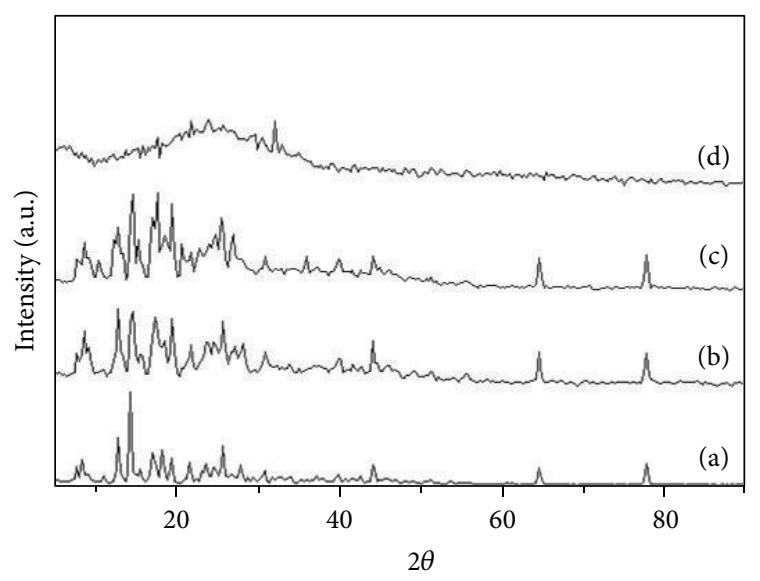

Figure 5: X-ray diffraction pattern of (a) Naringin, (b) NaringinBi (III) complex, (c) Naringin- $\beta$-CD inclusion complex, and (d) Naringin-Bi (III)- $\beta$-CD inclusion complex.

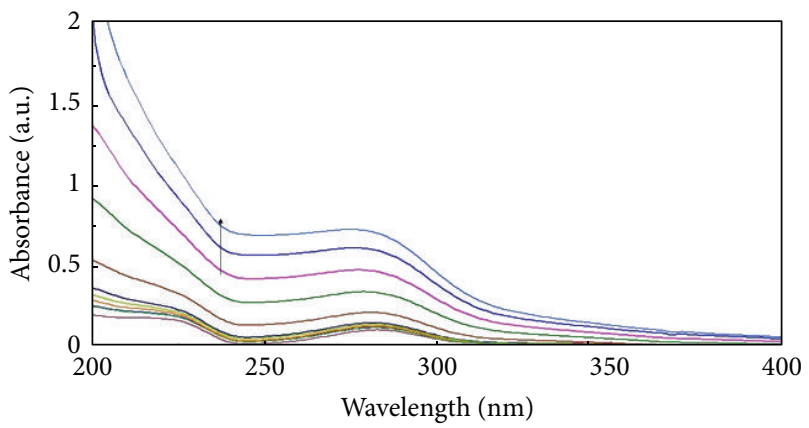

FIgURE 6: Absorption spectra of Naringin-Bi (III) in various concentrations of $\beta$-CD.

crystallinity due to inclusion complexation with $\beta$-CD. Using Debye-Scherrer formula (as given in (1)), the average of the crystallite size of Narg, Narb, and its inclusion complexes was calculated as 228, 170,202, and $337 \mathrm{~nm}$, respectively. Consider

$$
D=\frac{0.9 \lambda}{\beta \cos \theta},
$$

where $D$ is the size of the crystal, $\lambda$ is the wavelength of the radiation $(=1.5418 \AA), \theta$ is the diffraction angle, and $\beta$ is the broadening factor (half width measured at half its maximum intensity).

3.2. UV-Visible Absorption Analysis. The interaction of Narb with $\beta$-CD was carried out with the titration of Narb with varying concentrations of $\beta$-CD from 0 to $1 \times 10^{-2} \mathrm{~mol}$ $\mathrm{dm}^{-3}$. This titration was done with the UV-Visible absorption technique. When the concentration of $\beta$-CD increased, the absorbance was found to be increasing slowly at the initial concentrations of $\beta$-CD (Figure 6). The absorption maximum $\lambda_{\max }$ of Narb, found at $282 \mathrm{~nm}$ at the $0 \mathrm{~mol} \mathrm{dm}^{-3}$ concentration of $\beta-\mathrm{CD}$, was shifted to $275 \mathrm{~nm}$ at the $1 \times$ $10^{-2} \mathrm{~mol} \mathrm{dm}^{-3}$ concentration of $\beta$-CD. This showed the inclusion complexation of Narb with $\beta$-CD. The absorbance

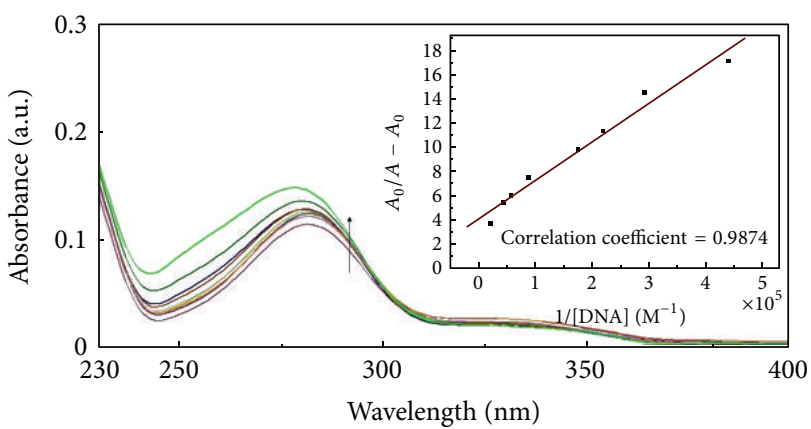

FIgURE 7: Absorption spectra of Naringin-Bi (III) in various concentrations of ctDNA (inset: the plot of $A_{0} / A_{s}-A_{0}$ against $1 /$ [DNA] for the interaction of Naringin-Bi (III) in various concentrations of ctDNA).

changes of Narb at the initial concentration of $\beta-\mathrm{CD}$ up to $2 \times 10^{-3} \mathrm{~mol} \mathrm{dm}^{-3}$ are too low to determine the binding constant for the inclusion complexation of Narb with $\beta$-CD by adopting the Benesi-Hildebrand for

$$
\text { Narb }+n \beta-\mathrm{CD} \longleftrightarrow \text { Narb- } \beta \text {-CD complex. }
$$

The interaction of Narb with ctDNA was analysed by the titration of Narb by varying concentration of ctDNA from 0 to $4.54 \times 10^{-5} \mathrm{~mol} \mathrm{dm}^{-3}$. As the concentration of ctDNA increases, the absorbance of Narb increases. The absorption maximum was shifted to $278 \mathrm{~nm}$ (Figure 7). This change in the absorption maximum of Narb with respect to ctDNA shows the strong electronic coupling of Narb with ctDNA. Equation (3) was utilized to find the binding constant for the interaction of Narb with ctDNA:

$$
\frac{A_{0}}{A-A_{0}}=\frac{\varepsilon_{G}}{\varepsilon_{H-G}-\varepsilon_{G}}+\frac{\varepsilon_{G}}{\varepsilon_{H-G}-\varepsilon_{G}} \frac{1}{K[\mathrm{DNA}]},
$$

where $A_{0}$ and $A$ are the absorbance of the free quest and the apparent one and $\varepsilon_{G}$ and $\varepsilon_{H-G}$ are their absorption coefficients, respectively. The plot of $A_{0} / A-A_{0}$ versus $1 /[\mathrm{DNA}]$ following equation (3) is shown in the inset of Figure 7. The binding constant of Narb-ctDNA was calculated as $1.29 \times 10^{5} \mathrm{~mol}^{-1} \mathrm{dm}^{3}$. The binding constant of NaringinctDNA was determined as $8.22 \times 10^{4} \mathrm{~mol}^{-1} \mathrm{dm}^{3}$ [4]. The higher binding affinity was observed for Bismuth complexed Naringin than Naringin for ctDNA.

The interaction of Narb with ctDNA was analysed by the titration of Narb- $\beta$-CD complex by varying concentration of ctDNA from 0 to $4.54 \times 10^{-5} \mathrm{~mol} \mathrm{dm}^{-3}$. As the concentration of ctDNA increased, the absorbance of Narb increased. The absorption maximum was shifted from $283 \mathrm{~nm}$ to $279 \mathrm{~nm}$ (Figure 8). This change in the absorption maximum of Narb with respect to ctDNA showed the interaction of Narb with ctDNA. Equation (2) was utilized to find the binding constant for the interaction of Narb with ctDNA. The binding constant calculated for the interaction of Narb with ctDNA was $6.89 \times$ $10^{4} \mathrm{~mol}^{-1} \mathrm{dm}^{3}$ (inset of Figure 8). A decrease in the binding affinity of Narb- $\beta$-CD in comparison with Narb with ctDNA was observed. This might be due to the competition between 


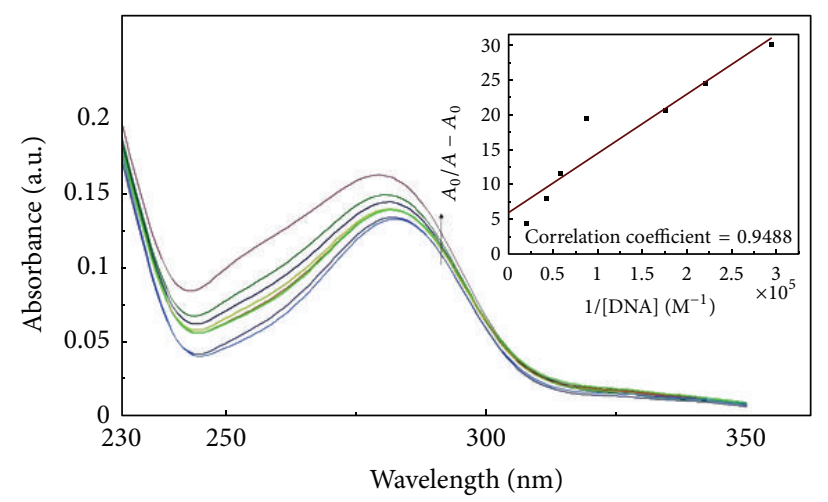

FIGURE 8: Absorption spectra of Naringin-Bi (III)- $\beta$-CD in various concentrations of ctDNA (inset: the plot of $A_{0} / A_{s}-A_{0}$ against $1 /[\mathrm{DNA}]$ for the interaction of Naringin-Bi (III)- $\beta$-CD in various concentrations of ctDNA).

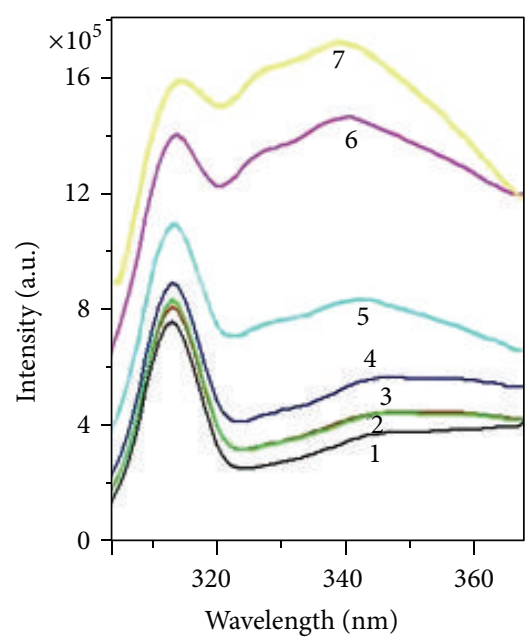

(a)

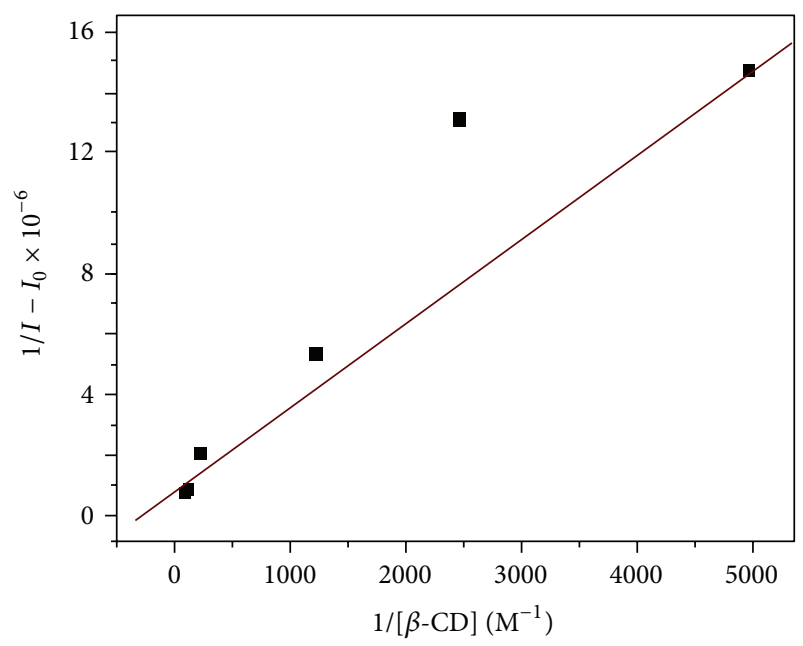

(b)

FIGURE 9: (a) Fluorescence spectra of Naringin-Bi (III) with different concentrations of $\beta$-CD, (b) Benesi-Hildebrand plot for Naringin-Bi (III) $/ \beta$-CD complex formation.

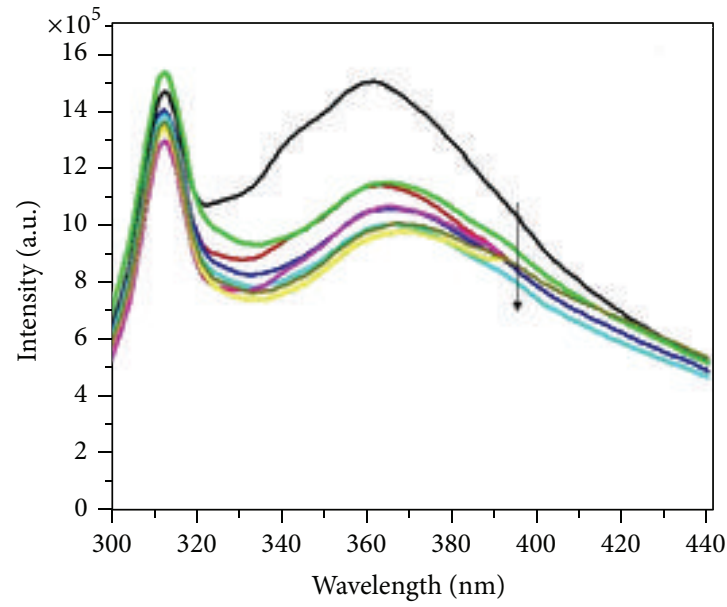

(a)

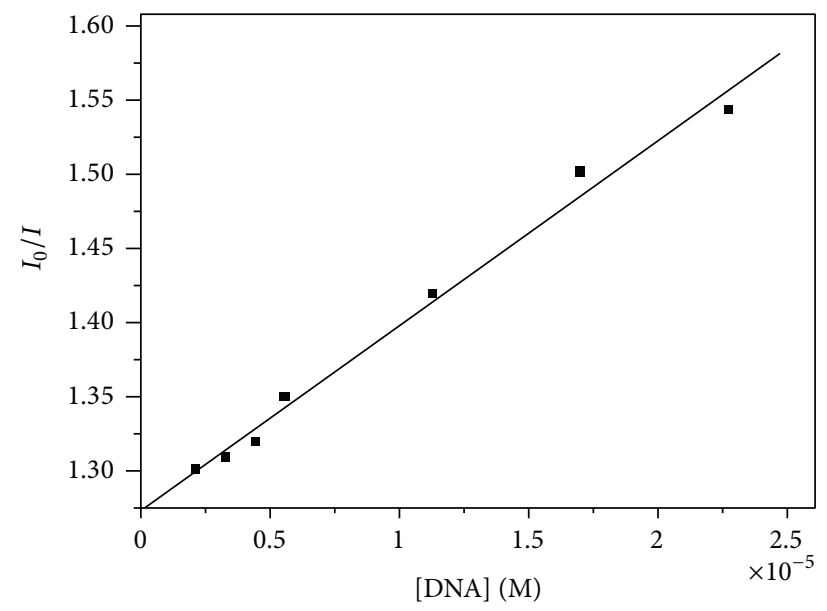

(b)

FIGURE 10: (a) Fluorescence spectra of Naringin-Bi (III) in the presence of various concentrations of ctDNA, (b) the plot of $I_{0} / I$ against [DNA] for the interaction of Naringin-Bi (III) in various concentrations of ctDNA. 


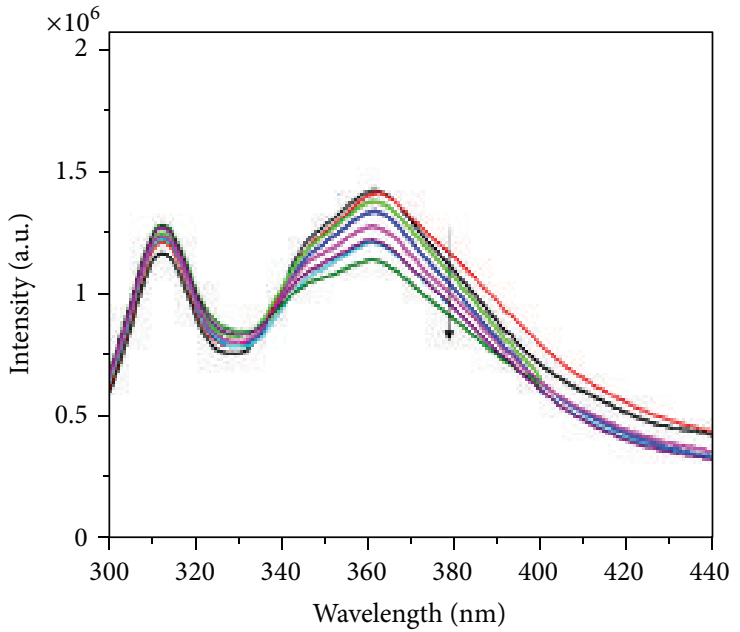

(a)

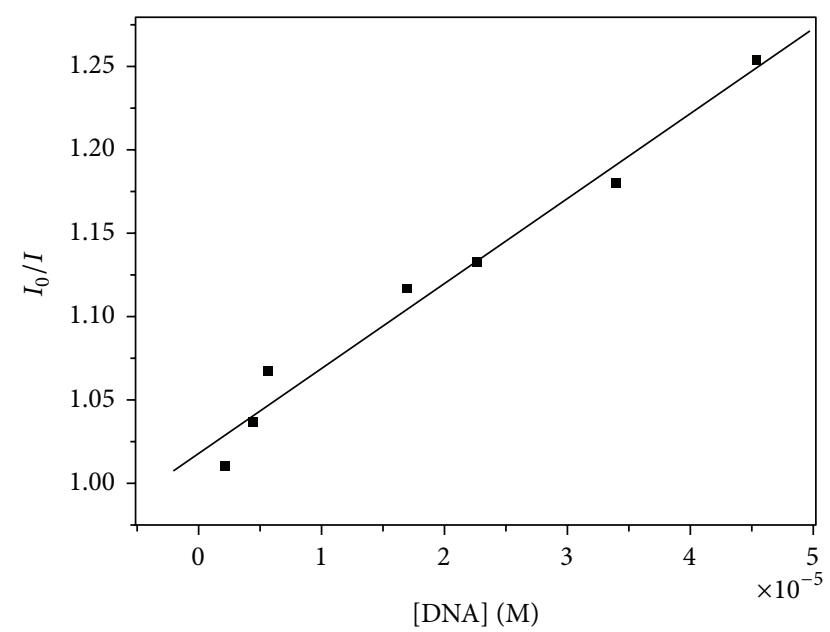

(b)

FIGURE 11: (a) Fluorescence spectra of Naringin-Bi (III)- $\beta$-CD in various concentrations of ctDNA, (b) the plot of $I_{0} / I$ against [DNA] for the interaction of Naringin-Bi (III)- $\beta$-CD in various concentrations of ctDNA.

$\beta$-CD and ctDNA for the interaction with Narb. Moreover, $\beta$-CD encapsulated form of Narb and Naringin showed no significant changes in their binding affinity with ctDNA.

3.3. Fluorescence Analysis. The interaction of Narb with $\beta$-CD was studied by the titration of Narb with varying concentrations of $\beta$-CD from 0 to $1 \times 10^{-2} \mathrm{~mol} \mathrm{dm}^{-3}$. This titration was done by the fluorescence technique. When the concentration of $\beta$-CD increased, the fluorescence intensity increased. The emission maximum $\lambda_{\text {emi }}$ of Narb is found at 313 and $362 \mathrm{~nm}$ in water (Figure 9(a)). The second band was shifted to $339 \mathrm{~nm}$ at the $1 \times 10^{-2} \mathrm{~mol} \mathrm{dm}{ }^{-3}$ concentration of $\beta$-CD. There was no considerable shift observed for the band observed at $313 \mathrm{~nm}$. The following equation was utilized to find the binding constant for the Narb- $\beta$-CD inclusion complex [14]:

$$
\frac{1}{I-I_{0}}=\frac{1}{I^{\prime}-I_{0}}+\frac{1}{I^{\prime}-I_{0}} \frac{1}{K[\beta-\mathrm{CD}]}
$$

The stoichiometry for the interaction of Narb with $\beta$ $\mathrm{CD}$ was of $1: 1$. The calculated binding constant was $5.18 \times$ $10^{2} \mathrm{~mol}^{-1} \mathrm{dm}^{3}$ for Narb- $\beta$-CD complex (Figure 9(b)). A 1:2 stoichiometric interaction was observed for Naringin and $\beta$-CD. This confirms the inaccessibility of chromen-4-one moiety of Naringin due to involvement with $\mathrm{Bi}$ (III) for metal complex formation.

The interaction of Narb with ctDNA was analysed by the titration of Narb by varying the concentration of ctDNA from 0 to $4.54 \times 10^{-5} \mathrm{~mol} \mathrm{dm}{ }^{-3}$. As the concentration of ctDNA increased, the emission of Narb increased. The emission maximum shifted from 362 to $369 \mathrm{~nm}$ (Figure 10(a)). This change in the emission maximum of Narb with respect to ctDNA shows the interaction of Narb with ctDNA. The following equation [15] was utilized to find the Stern-Volmer quenching constant for the interaction of Narb with ctDNA:

$$
\frac{F_{0}}{F}=1+K_{\mathrm{sv}}[Q]
$$

The Stern-Volmer quenching constant calculated for the interaction of Narb with ctDNA was of $1.25 \times 10^{4} \mathrm{~mol}^{-1} \mathrm{dm}^{3}$ (Figure 10(b)). The above quenching constant for interaction with ctDNA is lower than that of Naringin. The interaction of Narb with ctDNA was analyzed by the titration of Narb$\beta$-CD complex by varying the concentration of ctDNA. As the concentration of ctDNA increased, the fluorescence of Narb increased. The emission maximum was not shifted significantly from $360 \mathrm{~nm}$ (Figure 11(a)). This change in the emission maximum of Narb with respect to ctDNA showed the interaction of Narb with ctDNA. Equation (5) was utilized to find the Stern-Volmer quenching constant for the interaction of Narb with ctDNA. The Stern-Volmer quenching constant calculated for the interaction of Narb with ctDNA was of $5.10 \times 10^{3} \mathrm{~mol}^{-1} \mathrm{dm}^{3}$ (Figure $11(\mathrm{~b})$ ). The quenching constant for the binding of Narb and ctDNA in the presence of $\beta$-CD does not show more alterations than that of Naringin and ctDNA binding in the presence of $\beta$-CD. This observation is in accordance with UV-Visible absorption measurements. The lowering of the binding affinity and the $K_{\text {sv }}$ were observed for the binding of Narb with ctDNA in the presence of $\beta$-CD. This infers that the inclusion complexation of Narb with $\beta$-CD resulted in the weakening of the binding strength between Narb and ctDNA. A higher binding affinity was observed for Naringin-Bi (III) than Naringin for ctDNA, whereas there are no many changes in the binding strength of $\beta$-CD encapsulated Naringin/Naringin-Bi (III) towards ctDNA observed by both the UV-Visible absorption and fluorescence techniques. 


\section{Conclusion}

The 2:1 stoichiometric interaction between Naringin and Bi (III) was observed. The 1:1 inclusion complexation of Naringin-Bi (III) complex with $\beta$-CD was realized. This is in contrast to the reported $1: 2$ ratio for Naringin and $\beta$-CD. The lowering of the binding affinity and the $K_{\mathrm{sv}}$ were observed for the binding of Narb with ctDNA in the presence of $\beta$-CD. This infers that the inclusion complexation of Narb with $\beta-\mathrm{CD}$ resulted in the weakening of the binding strength between Narb and ctDNA. A higher binding affinity was observed for Naringin-Bi (III) than Naringin for ctDNA, whereas there are no many changes in the binding strength of $\beta$ CD encapsulated Naringin/Naringin-Bi (III) towards ctDNA observed. Thus the Bi (III) complexation with Naringin may have a significant role in deciding the stoichiometry of the Naringin- $\beta$-CD inclusion complex and in binding strength of Naringin with ctDNA in the absence and the presence of $\beta$-CD.

\section{Conflict of Interests}

The authors declare that there is no conflict of interests.

\section{References}

[1] F.-Y. Wu, F.-Y. Xie, Y.-M. Wu, and J.-I. Hong, "Interaction of a new fluorescent probe with DNA and its use in determination of DNA," Journal of Fluorescence, vol. 18, no. 1, pp. 175-181, 2008.

[2] C. Cai, X. Chen, and F. Ge, "Analysis of interaction between tamoxifen and ctDNA in vitro by multi-spectroscopic methods," Spectrochimica Acta Part A, vol. 76, no. 2, pp. 202-206, 2010.

[3] R. J. Nijveldt, E. Van Nood, D. E. C. Van Hoorn, P. G. Boelens, K. Van Norren, and P. A. M. Van Leeuwen, "Flavonoids: a review of probable mechanisms of action and potential applications," The American Journal of Clinical Nutrition, vol. 74, no. 4, pp. 418-425, 2001.

[4] S. Yousuf and I. V. M. V. Enoch, "Binding interactions of naringenin and naringin with calf thymus DNA and the role of $\beta$-cyclodextrin in the binding," AAPS PharmSciTech, vol. 14, no. 2, pp. 770-781, 2013.

[5] A. A. Ensafi, R. Hajian, and S. Ebrahimi, "Study on the interaction between morin-Bi(III) complex and DNA with the use of methylene blue dye as a fluorophor probe," Journal of the Brazilian Chemical Society, vol. 20, no. 2, pp. 266-276, 2009.

[6] Y. Sameena and I. V. M. V. Enoch, "The influence of $\beta$ cyclodextrin on the interaction of hesperetin and its bismuth (III) complex with calf thymus DNA," Journal of Luminescence, vol. 138, pp. 105-116, 2013.

[7] N. Burford, M. D. Eelman, and K. Groom, "Identification of complexes containing glutathione with $\mathrm{As}(\mathrm{III}), \mathrm{Sb}(\mathrm{III}), \mathrm{Cd}(\mathrm{II})$, $\mathrm{Hg}(\mathrm{II}), \mathrm{Tl}(\mathrm{I}), \mathrm{Pb}(\mathrm{II})$ or $\mathrm{Bi}(\mathrm{III})$ by electrospray ionization mass spectrometry," Journal of Inorganic Biochemistry, vol. 99, no. 10, pp. 1992-1997, 2005.

[8] J. R. Lambert and P. Midolo, "The actions of bismuth in the treatment of Helicobacter pylori infection," Alimentary Pharmacology and Therapeutics, vol. 11, no. 1, pp. 27-33, 1997.

[9] T. Frank, B. Beatrixand, and H. Reinhard, "Medical use of bismuth: the two sides of the coin," Journal of Clinical Toxicology, vol. 3, pp. 1-5, 2011.
[10] F. Mégraud, "The challenge of Helicobacter pylori resistance to antibiotics: the comeback of bismuth-based quadruple therapy," Therapeutic Advances in Gastroenterology, vol. 5, no. 2, pp. 103$109,2012$.

[11] G.-C. Zhao, J.-J. Zhu, J.-J. Zhang, and H.-Y. Chen, "Voltammetric studies of the interaction of methylene blue with DNA by means of $\beta$-cyclodextrin," Analytica Chimica Acta, vol. 394, no. 2-3, pp. 337-344, 1999.

[12] R. M. S. Pereira, N. E. D. Andrades, N. Paulino et al., "Synthesis and characterization of a metal complex containing naringin and $\mathrm{Cu}$, and its antioxidant, antimicrobial, antiinflammatory and tumor cell cytotoxicity," Molecules, vol. 12, no. 7, pp. 13521366, 2007.

[13] A. Farcas, N. Jarroux, P. Guegan, V. Harabagiu, and V. Melnig, "Synthesis of fluorene copolymer with persilylated $\gamma$ cyclodextrin in the main chain," Journal of Optoelectronics and Advanced Materials, vol. 9, no. 11, pp. 3484-3488, 2007.

[14] D. W. Cho, Y. H. Kim, S. G. Kang, M. Yoon, and D. Kim, "Cyclodextrin effects on intramolecular charge transfer of 2biphenylcarboxylic acid: a pre-twisted molecule," Journal of the Chemical Society, Faraday Transactions, vol. 92, no. 1, pp. 29-33, 1996.

[15] J. R. Lakowicz, Principles of Fluorescence Spectroscopy, Plenum, New York, NY, USA, 1999. 

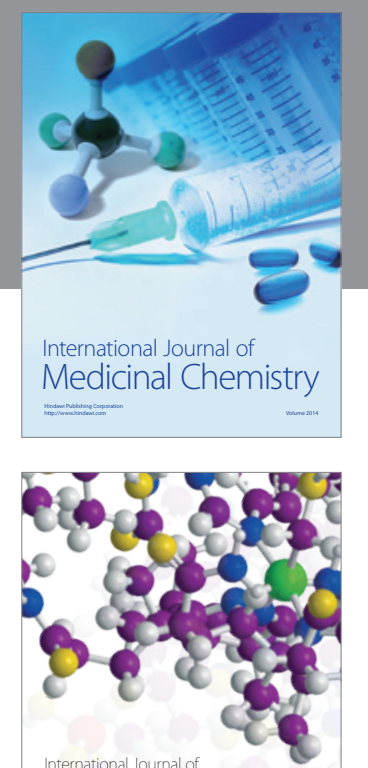

\section{Carbohydrate} Chemistry

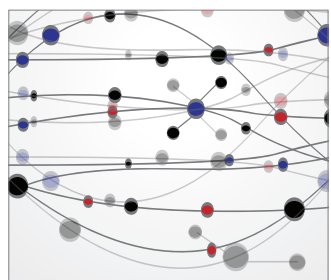

The Scientific World Journal
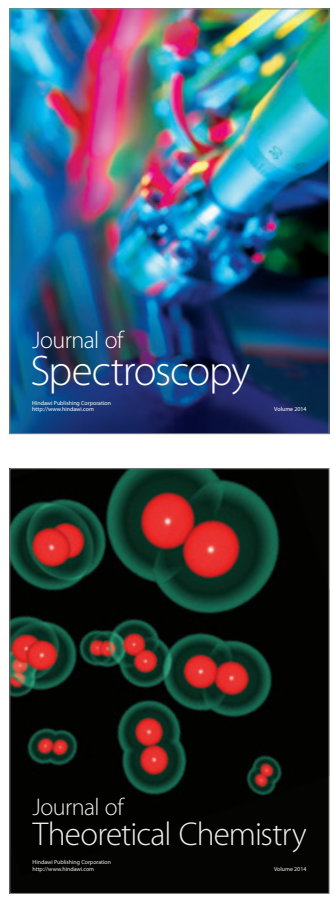
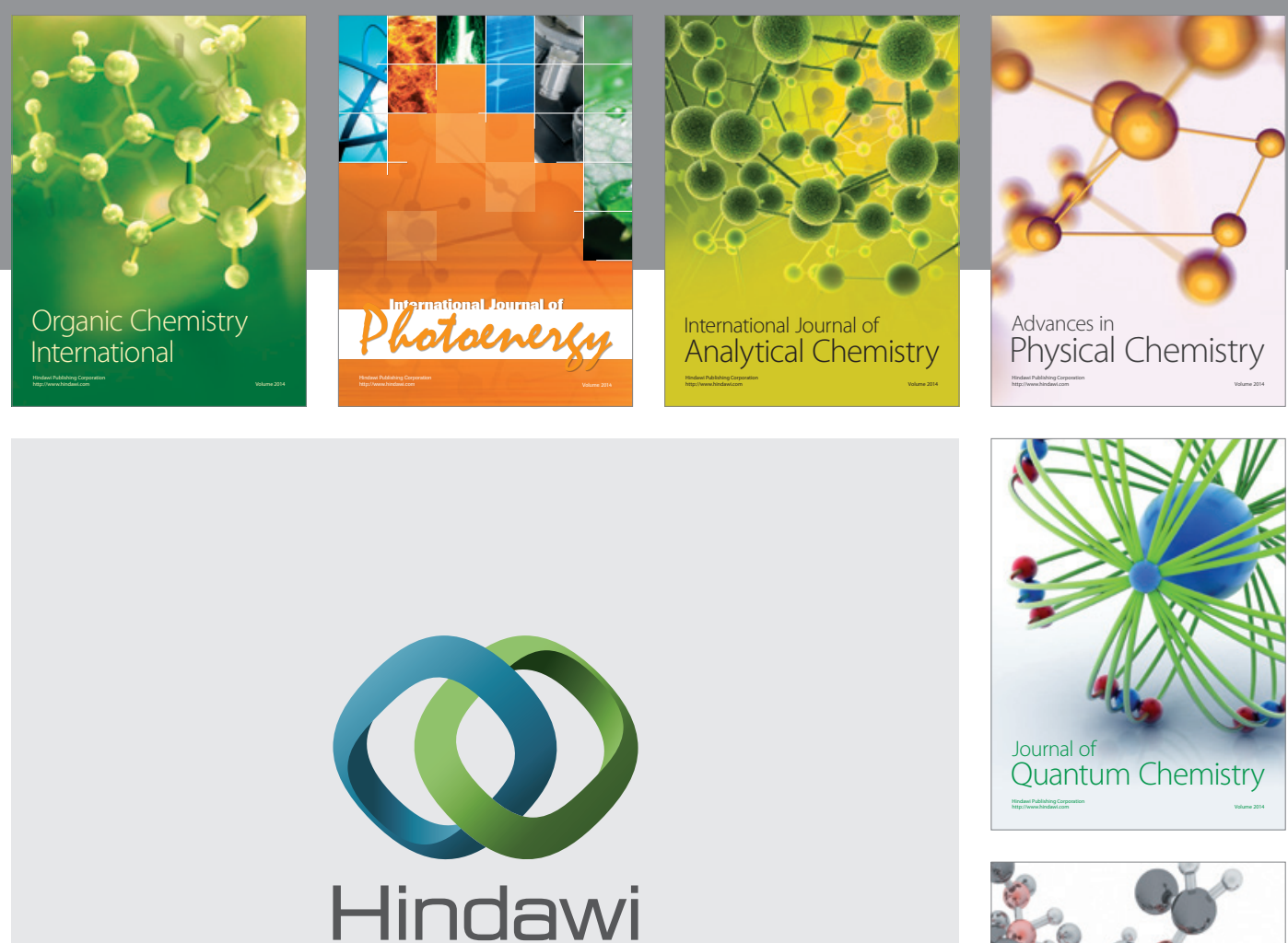

Submit your manuscripts at

http://www.hindawi.com

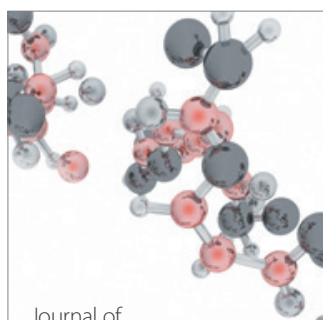

Analytical Methods

in Chemistry

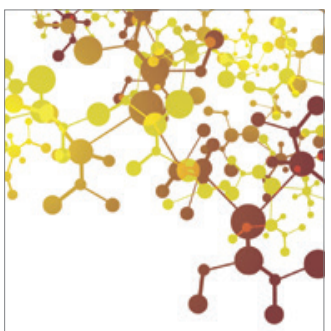

Journal of

Applied Chemistry

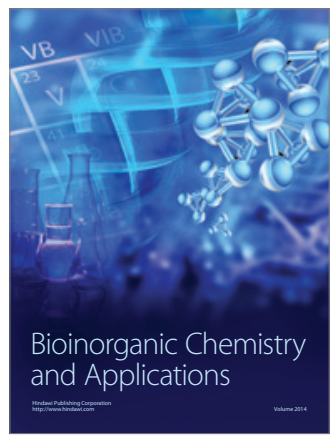

Inorganic Chemistry
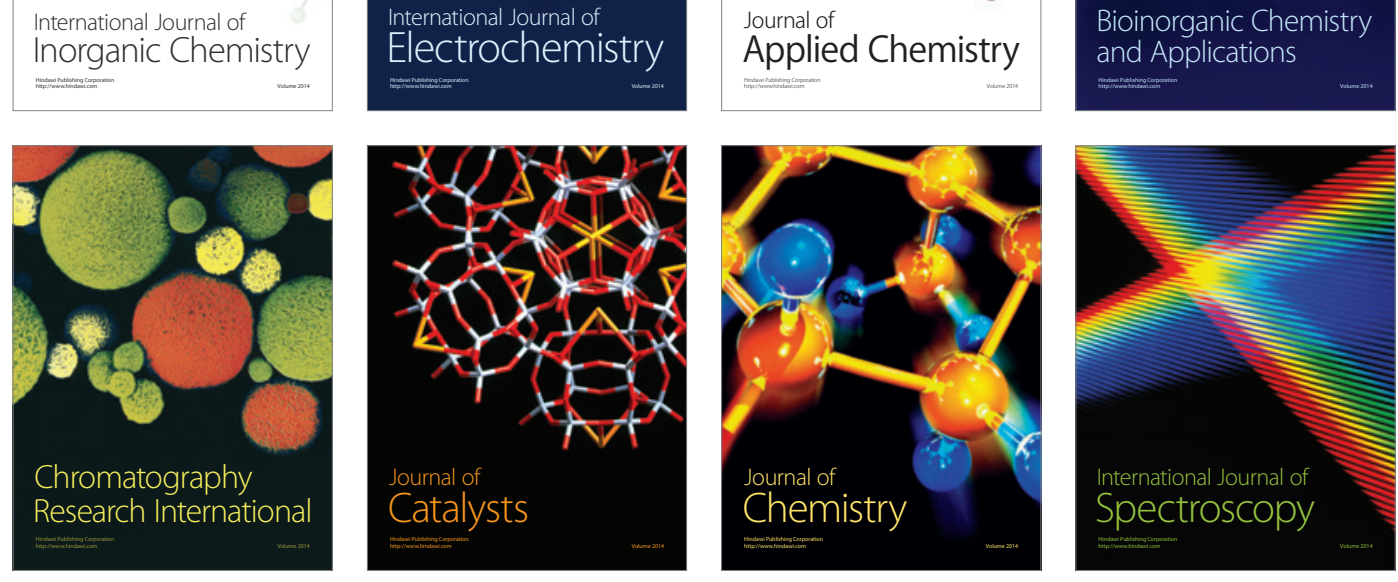